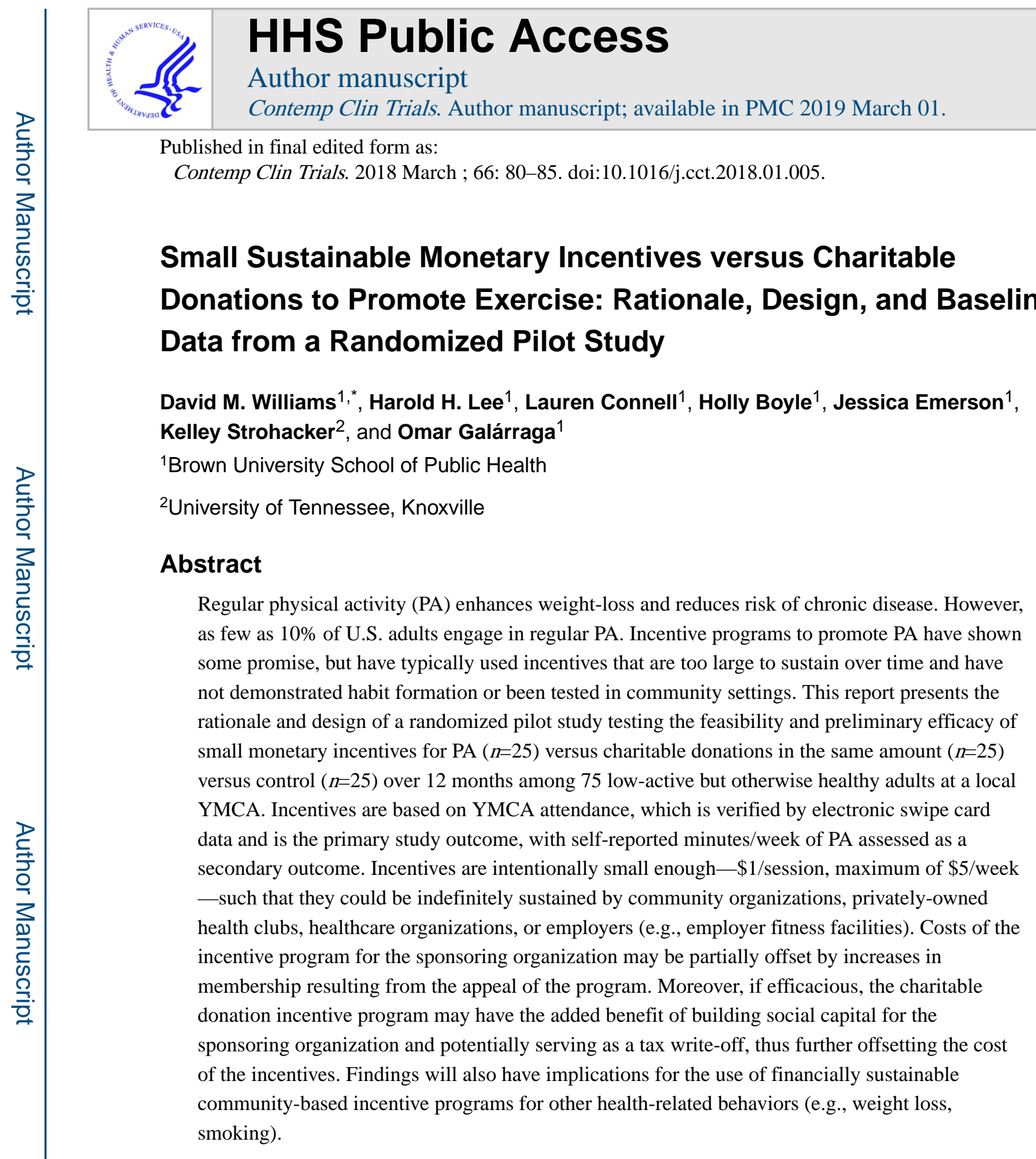

\title{
Introduction
}

Participation in regular physical activity (PA) has numerous health benefits including reduced risk of all-cause mortality,[1-7] cardiovascular disease,[8-12] diabetes,[13-16] and

\footnotetext{
"Corresponding Author: David M. Williams, Brown University School of Public Health, Box G-S121-4, Providence, RI 02912, USA, Tel: +1 (401) 863-6248, david_m_williams@ brown.edu.

Publisher's Disclaimer: This is a PDF file of an unedited manuscript that has been accepted for publication. As a service to our customers we are providing this early version of the manuscript. The manuscript will undergo copyediting, typesetting, and review of the resulting proof before it is published in its final citable form. Please note that during the production process errors may be discovered which could affect the content, and all legal disclaimers that apply to the journal pertain.
} 
cancers of the breast[17-19] and colon.[20-23] However, only 51.6\% of U.S. adults meet national guidelines of expending $\geq 1000 \mathrm{kcals} /$ week through PA,[24] and estimates are as low as $10 \%$ meeting these guidelines when objective assessments of PA are used.[25]

One promising approach to exercise promotion is the use of material incentives. In operant conditioning theory, an incentive is a stimulus that is presented contingent on performance of a specified behavior for the purposes of increasing the frequency of the behavior (aka, contingency management).[26, 27] In behavioral economics, conditional economic incentives (aka, conditional cash transfers) are used to "nudge" participants into adopting behaviors they want to pursue, but struggle to achieve because of departures from fully "rational" behavior.[28, 29] For example, even though most of us recognize the benefits of exercise, we may be temporarily "myopic"-preferring to watch TV and delay exercising. [30-33]

A recent systematic review of the use of material incentives in exercise promotion programs yielded 12 randomized controlled trials that, while heterogeneous regarding incent ive type, structure, and sample population, supported the use of incentives to promote initial increases in exercise behavior.[34] However, there was no evidence of habit formation, meaning that patterns of exercise behavior tend to return to baseline following removal of the incentive program. Moreover, no RCTs tested the efficacy of incentive programs for exercise promotion in real-world community settings.

This paper presents the rationale and design of a randomized pilot study comparing two community-based (i.e., YMCA) exercise promotion incentive programs that are designed to be indefinitely financially sustainable and thus alleviate the need for removal of the incentives. In both incentive programs, participants pay the standard monthly YMCA membership fee of $\$ 49 /$ month. In the Rebate incentive program, participants have the opportunity to earn $\$ 1 /$ day for each day that they attend the YMCA (verified by objective swipe-card data), with a maximum of $\$ 5 /$ week. In the Donation incentive program, participants have the opportunity to earn $\$ 1 /$ day (using the same incentive schedule) in donations to a registered local charity of the participant's choice. The Rebate and Donation conditions are compared to a control condition that receives only feedback on their attendance.

Although this pilot study is not adequately powered to detect significant between-group differences, we expect that the average number of days per week of YMCA attendance will be greater for those in the Rebate and Donation conditions as compared to the Control condition. In addition to our primary hypotheses, we will explore the moderating effects altruism and hedonic and eudaimonic well-being on the efficacy of each incentive intervention. Specifically, we expect that the Rebate intervention will be more efficacious, relative to control, for those who score high on hedonic well-being, and the Donation intervention will be more efficacious, relative to control, for those who score high in eudaimonic well-being and altruism. 


\section{Proof-of-Concept Study}

Prior to conducting the pilot study that is the focus of the present paper, we conducted an initial 10-week study to determine proof-of-concept for the use of small monetary incentives among a sample of 22 sedentary or low active university students (20 \pm 1.6 years, body mass index $24 \pm 3.5 \mathrm{~kg} / \mathrm{m}^{2}, 69 \%$ women, $41 \%$ non-Hispanic white).[35] Participants were randomized to either a control condition (non-incentivized, $\mathrm{n}=11$ ) or an experimental condition ( $n=11$ ) to earn $\$ 0.01$ per every 4 kilocalories expended through aerobic exercise performed at the university fitness center. Incentives were capped at $\$ 5.00$ per week, equivalent to a caloric expenditure of 2000 kilocalories as this value represents the upper end of national recommendations for aerobic activity.[36] Caloric expenditure data were collected two ways: a) participants in the first cohort downloaded exercise session data using USB drives and uploading to an equipment-specific website, and b) participants in the second cohort took photos of exercise session summaries displayed on equipment monitors using smartphones and emailed photos to the study staff. All reported sessions were verified using electronic swipe card data from the University fitness center. Participants in the control and experimental conditions were provided with weekly emails highlighting his or her weekly total regarding caloric expenditure and caloric expenditure plus cash earned, respectively. All earned incentives were provided upon study completion. While this initial study was underpowered (62\%), we observed a medium interaction effect (Cohen's d $=.69$ ) in favor of the incentivized condition regarding caloric expenditure over time $\left(F_{(1,171)}=\right.$ $2.25, \mathrm{p}=.06$ ), thus providing proof-of-concept for the larger pilot study.

\section{Methods}

\section{Recruitment and Screening}

The study was conducted at the Kent County YMCA in Warwick, Rhode Island, USA. Recruitment targeted adults ( $\geq 18$ years) who either joined the YMCA within the past week (hereafter referred to as new members) or were previous YMCA members with low attendance, defined as attending the YMCA fewer than 4 times per month in the last 6 months as verified through the YMCA database. Recruitment channels included YMCA new-member orientation, word of mouth by participants and YMCA staff, flyers in the YMCA and local community, and targeted postcards, emails, and phone calls from both the YMCA staff and research staff.

Regardless of recruitment channel, participants were required to express interest in the study by sending an email to the study email address. Study staff then checked the YMCA database to ensure the participant was $\geq 18$ years, had an active YMCA membership (\$49/ month plus a $\$ 49$ joiners fee; rates are reduced for those $\leq 23$ or $\geq 62$ years-old, as well as for those who can verify need for financial assistance),[37] and was either a new member or met the low attendance criteria. Those who met these initial screening criteria were directed to an online consent form, followed by an additional screen for eligibility. Additional eligibility criteria included engaging in fewer than 150 minutes/week of structured moderate intensity exercise 75 minutes/week of vigorous intensity exercise or an equivalent combination of moderate and vigorous intensity exercise; plans to reside in the geographical region for the next 12 months; and no enrolled/participating family members. 


\section{Baseline Assessments and Randomization}

Participants who were eligible after the screening completed a baseline survey assessing demographic characteristics, height, weight, altruism, and hedonic and eudaimonic wellbeing. Upon completion of the baseline survey, participants were randomized into Rebate $(n=25)$, Donation $(n=25)$, or Control $(n=25)$ using a stratified permuted blocks randomization procedure, with respect to the strata of overweight/obesity status, such that a roughly equal number of participants in each condition with BMI $<25.0,25.0 \leq \mathrm{BMI}<30.0$, and BMI $\geq 30$. Participants were asked to not reveal to YMCA staff which experimental condition they were randomized to.

\section{Experimental Conditions}

Rebate-Participants in the Rebate condition have the opportunity to earn \$1/day in monetary incentives over a 12-month period in the form of Amazon.com credits for each day that they attend the YMCA (verified by objective swipe-card data), with a maximum of $\$ 5 /$ week. Notice of these incentives is provided to participants on a weekly basis via email such that participants will be able to track their total incentives for the week and year-to-date. The incentive for the previous week is made available to participants at the beginning of the following week. Additionally, upon study enrollment participants receive an initial priming incentive of $\$ 5$.

Donation incentive condition-Participants in the Donation condition have the opportunity to earn $\$ 1 /$ day in donations to a registered local charity of their choice for each day that they attend the YMCA over a 12-month period. As with the rebate condition, notice of donations are sent to participants each week via email and participants receive an initial priming incentive of $\$ 5$ upon study enrollment.

Control condition-Participants in the Control condition are provided with weekly emails about their YMCA attendance over a 12-month period, but do not receive incentives.

\section{Exercise Prescription}

As part of the normal YMCA orientation process, and prior to study enrollment, participants in all three experimental conditions received exercise prescriptions for achieving at least 30 $\mathrm{min}$ /day of moderate-intensity exercise, with moderate intensity based on 64-76\% of agepredicted maximal heart-rate (i.e., $\mathrm{HR}_{\max }=206.9-(0.67 \times$ age $)$ ) or Rated Perceived Exertion of 13-15.[36] Participants were instructed via YMCA staff that exercise prescriptions can be met through use of the treadmills, ellipticals, and stationary cycles available at the YMCA as well as through swimming or participation in YMCA structured exercise classes, which include step aerobics, Zumba, and cardio boxing and are available to members at no extra charge. All participants were asked to only swipe their membership card when they were at the YMCA to exercise.

\section{Exercise Tracking}

Exercise attendance is tracked through the YMCA on-line attendance tracking system. Two parameters are tracked and used to compare the exercise performed by the three study 
conditions. First, attendance at the YMCA is automatically tracked by the YMCA swipecard system. Although this study was based at the Kent County YMCA, attendance data was captured if participants attended any of the seven Greater Providence YMCA branches. Weekly emails sent to participants provide an update about their gym attendance for the previous week, as well as their total attendance during study. Participants in the two incentive conditions are incentivized based on the objectively monitored number of days of attendance at the YMCA, with only one swipe reading incented per day. Participants can also view their attendance at the YMCA for the previous two months when they log on to the tracking system either via smart-phone app or website-including on computer terminals at the local YMCA. Second, participants are asked to complete a questionnaire about their average exercise behavior in number of minutes, assessed via the Godin Leisure Time Exercise Questionnaire at months 3, 6, 9 and 12 post-randomization. Participants are provided with email and phone call reminders and are compensated $\$ 10$ for the completion of each follow-up questionnaire. Number of minutes of PA will be considered a secondary outcome.

The University's Institutional Review Board approved all study procedures. The protocol is registered in ClinicalTrials.gov, with identifier: NCT03134040.

\section{Measures}

Primary outcome-The primary outcome is the average number of objectively verified days of attendance per week at the YMCA over one year.

Secondary outcomes-Secondary outcomes are average minutes per week of exercise at the YMCA and total minutes of exercise per week completed inside and outside the YMCA, assessed using a modified version[38] of the Godin Leisure Time Exercise Questionnaire[39] that includes frequency and duration of PA. We further modified the questionnaire to ask specifically about exercise at the YMCA and outside the YMCA, as well as to gauge whether participants' exercise behavior at the time of completing the questionnaire was the same, more, or less than in the previous three months.

Putative moderators-Hedonic well-being was assessed using the Subjective Happiness Scale (Lyubomirsky et al., 1999). The scale consists of four items, which participants rate on a 1-7 scale (e.g., "In general, I consider myself .... 1= not a very happy person ... $7=$ a very happy person"). Eudaimonic well-being was assessed using the Life Engagement Test (Scheier et al., 2006), which measures the extent to which an individual engages in personally valued activities. The scale consists of six items (e.g., "To me, the things I do are worthwhile"), which participants rate on a 1-5 scale ( $1=$ Strongly Disagree, $5=$ Strongly Agree). Altruism was assessed using the Self-report Altruism Scale.[40] The scale consists of 20 items (e.g., "I have helped push a stranger's car out of snow), which participants rate on a $1-5$ scale $(1=$ Never, $5=$ Very often $)$.

Potential covariates-We will examine demographic variables and any observed differences in exercise performed outside the YMCA as potential covariates in our primary analyses. 


\section{Planned Analyses}

Primary and secondary outcome analyses-We will first test for balance of the main covariates across the control and each of the experimental arms. The primary outcome analysis will be structured such that treatment comparisons are made based on the principle of "intention-to-treat", and the primary outcome data will be analyzed using all participants initially randomized to treatment. For the primary analysis we will use generalized linear mixed models (GLM), which accommodate longitudinal count data, such as number of days of attendance per week over an observation period of 52 weeks for each individual, (using Poisson or negative binomial distributions) as well as missing values under the assumption of missing at random (MAR)[41], and will allow for maximum use of the measured data to detect a treatment effect. We plan to test the dispersion of the attendance count data to determine if the data are better suited to a Poisson, or negative binomial model. If, based on the preliminary analyses noted above, there are baseline treatment group differences on key demographic, PA, or psychosocial variables that might affect treatment outcomes, then analysis will be restructured to include such variables as additional covariates within the ANCOVA. At the end of the trial we will determine if any missing data are MAR, of if any differential attrition needs to be accounted for. The above analyses will be repeated for the secondary outcome, total minutes of exercise completed outside the YMCA, as indicated in the monthly online Godin Leisure Time Physical Activity Questionnaire. In this analysis, we will assess the distribution of the data to determine whether it follows a normal distribution. The main coefficients of interest will be the treatment-by-time interactions, after controlling for the main effects: treatment arm (rebate or donation vs. control) and time (week).

A sample size of 25 per condition was chosen to ensure a reasonable estimate of the effects of the two incentive programs compared to controls. Given the nature of longitudinal research, and the length of follow-up, we expect to analyze up to 3,900 observations per outcome ( 75 people $\times 52$ weeks), though some proportion of participants are expected to be lost to follow-up. Although we do not expect to have sufficient power (power is estimated at $66 \%$ ) to detect statistically significant differences between the groups, we do expect to see differences between the groups that would be clinically meaningful if applied to a large enough population (i.e., across all seven Greater Providence YMCAs). Specifically, we will consider it clinically meaningful if we observe effect sizes of $\geq .30$ for either of the two incentive programs, thus approximating the small-to-moderate threshold based on Cohen. [42] Indeed, Even small additional amounts of physical activity (i.e. increases of 15 minutes per week) are associated with a decreased risk of death due to cancer, cardiovascular disease, diabetes, and all-cause mortality, thus even small changes in physical activity as a result of the intervention have the potential to improve the health of participants (Warburton \& Bredin, 2016).[43]

Moderator analyses-We also plan to assess whether any treatment effects are moderated by participants' altruism and hedonic and eudaimonic well-being. We will add additional interaction terms to measure the main effects (incentives, time, and well-being scales), as well as the second-order and third-order interactions using extensions of the GLM models. 


\section{Baseline Findings}

\section{Participant Recruitment}

A higher proportion of YMCA members responded to our recruitment channels if they were new members $(n=268 ; 23 \%)$, than if they were an existing member $(n=95 ; 12 \%)$. Of the 95 existing YMCA members with low attendance, 55 were excluded via a brief additional prescreen self-report survey, whereas 28 self-reported attending the YMCA too frequently, and $27 \mathrm{did}$ not respond. In total, $308 \mathrm{YMCA}$ members were assessed for eligibility to enroll in the study. Of those assessed for eligibility, the most frequently reported source of recruitment was a phone call from the study staff $(n=127 ; 41 \%)$, followed by an email either from the YMCA staff $(n=72,23 \%)$ or the study staff $(n=45,15 \%)$. Phone calls and emails from YMCA or study staff accounted for $79 \%$ of interested participants, with mailed postcards and flyers distributed both in the community, and in every new member folder accounting for an additional $17 \%$ of interested participants. Of those assessed for eligibility and then excluded, the primary reason for exclusion was not starting the eligibility screening survey $(n=156 ; 67 \%)$, followed by exercising too frequently $(n=46,20 \%)$. Recruitment was stopped after enrolling 25 participants into each condition (see Figure 1).

\section{Participant Characteristics}

The final sample enrolled was mostly female (82.7\%), white (92\%), had a college education $(67.6 \%)$, married (61.3\%), and had children under the age of 18 living with them (68\%).

Nearly half of the sample earned more than $\$ 50,000 /$ year $(45.3 \%)$, and over one-third were not employed (36.5\%). On average, participants were nearly 40 years old $(M=39.7$, $S D=12.3$ ), and had a BMI that would be categorized as overweight to obese ( $M=30.6$, $S D=7.8$ ). Assessment of between-group differences on baseline characteristics suggest that the random allocation of participants, stratified by BMI class was largely successful.

However, participants in the Rebate condition are significantly older than participants in the Donation condition, and less likely to be employed than participants in Donation and Control (see Tables 1 and 2 for more demographic information by experimental condition).

\section{Discussion}

This paper reports on the design of an ongoing randomized pilot study comparing two different financial incentive programs for exercise promotion to a control condition among previously low-active adults. Previous studies of financial incentives for exercise promotion have shown initial efficacy, but exercise levels typically return to baseline after incentives are removed, thus indicating a lack of habit formation. Thus, an alternative, innovative approach that we have taken in the present study is to test incentive levels that can continue indefinitely. We are also testing a donation incentive condition in which the incentives are donated to a charity of the participant's choice. Finally, we are conducting the study in the community-based setting of the YMCA. The rationale for each of these design features is discussed in more detail below. 


\section{Rationale for Specific Design Aspects}

Small financially sustainable incentives-Most previous health-behavior incentive programs have used financial incentives that are large and thus not financially sustainable over time. As a result, the incentives must ultimately be removed, which has typically resulted in participants returning to their baseline patterns of behavior.[34] The present study tests incentive programs in which incentives are small enough to be continued indefinitely by the sponsoring organization. Specifically, the proposed rebate program of $\$ 1$ per day with a maximum of $\$ 5$ per week was deemed - through consultation with YMCA managementto be the largest financial incentive that could be indefinitely continued.

Donations as incentives-In addition to the rebate incentive program, we are testing a donation incentive program using the same incentive schedule and amount as the rebate program, but with the earned incentives going to a local charity of the participant's choice. The decision to test a donation incentive program is based on two premises. First, participants' tendency to feel good when making a donation to a charity of their choosing, [44] should facilitate an association between exercise behavior and the positive feeling of helping others, which will thus lead to increases in exercise behavior.[45-47] Second, if efficacious, potential sponsoring organizations may prefer the donation program to the rebate incentive program because it has the potential to provide a tax write-off for the sponsoring organization and to increase social capital by helping the local community.

Community-based-The pilot study is being conducted at a local YMCA. The YMCA is an ideal partner for testing community-based incentive programs, because it has the potential for high reach if one or both of the programs are found to be efficacious, as $80 \%$ of all Americans live within a 3-mile radius of a YMCA. Additionally, findings may be applicable to private health centers and gyms, as such businesses are already interested in increasing the number of members using financially sustainable incentives for participation (e.g., see economic incentives information from the National Independent Health Club Association). [48]

\section{Alternate Design Considerations}

We considered asking participants to give an initial deposit of $\$ 10 /$ month beyond the normal YMCA membership fee to emulate previously successful deposit/rebate (i.e., negative reinforcement) incentive programs[49,50] and to make the incentive program more financially viable for the YMCA and for businesses that might choose to adopt the program if it is found to be efficacious. We decided against asking for this additional $\$ 10$ fee for two reasons. First, from the participants' perspective, a deposit is already being made in the form of the standard YMCA membership fee, thus the proposed incentive program-as currently formulated-is a deposit/rebate program even without an additional $\$ 10$ fee. Second, we viewed it as unethical and impractical to ask research volunteers to pay a fee to participate in the study.

We also considered an experimental condition in which participants are able to choose either rebates or donations in their name. While we continue to view the latter as a viable approach for practical application, we decided that for research purposes it would be preferable to 
randomize participants to one of these three conditions to provide a clear test of both the rebate and donation programs against controls-comparisons that could have theoretical as well as practical implications.

We considered opening the study to all adults regardless of prior activity level. However, we decided to include only those engaging in fewer than $150 \mathrm{~min} /$ week of structured moderate intensity exercise, or $75 \mathrm{~min} /$ week of vigorous intensity exercise (or an equivalent combination) in order to reach those most in need of exercise promotion programs.

\section{Limitations and Future Directions}

The biggest limitations of the present study are the small sample size and the relatively short duration of follow-up (12 months). If the pilot study yields a clinically meaningful effect size, we will propose to conduct a larger RCT with adequate statistical power to detect significant effects, as well as a 24-month follow-up to ensure that the effects are maintained over time. If one or both of the incentive programs are found to be efficacious in such a trial, those programs would immediately be viable for dissemination in YMCAs throughout the country. In addition to providing a fast-track for a potential ready-to-use intervention for the YMCAs, the lessons learned from testing the proposed incentive programs will be applicable to privately-owned and operated health centers, as well as other organizations looking to implement health-behavior incentive programs (e.g., large corporations, health insurance companies).[51]

\section{Acknowledgments}

Funding: This work was supported by the National Institutes of Health, National Cancer Institute (R03CA188473).

\section{References}

1. Lee IM, et al. Physical activity and coronary heart disease in women: Is "no pain, no gain" passe? Journal of the American Medical Association. 2001; 285(11):1447-54. [PubMed: 11255420]

2. Andersen LB, et al. All-cause mortality associated with physical activity during leisure time, work, sports, and cycling to work. Arch Intern Med. 2000; 160(11):1621-8. [PubMed: 10847255]

3. Autenrieth CS, et al. Association between domains of physical activity and all-cause, cardiovascular and cancer mortality. Eur J Epidemiol. 2011; 26(2):91-9. [PubMed: 21153912]

4. Lollgen HA, Bockenhoff G. Knapp, Physical activity and all-cause mortality: an updated metaanalysis with different intensity categories. Int J Sports Med. 2009; 30(3):213-24. [PubMed: 19199202]

5. Paffenbarger RS Jr, et al. Physical activity, all-cause mortality, and longevity of college alumni. N Engl J Med. 1986; 314(10):605-13. [PubMed: 3945246]

6. Petersen CB, et al. Changes in physical activity in leisure time and the risk of myocardial infarction, ischemic heart disease, and all-cause mortality. Eur J Epidemiol. 2012; 27(2):91-9. [PubMed: 22311520]

7. Woodcock J, et al. Non-vigorous physical activity and all-cause mortality: systematic review and meta-analysis of cohort studies. Int J Epidemiol. 2011; 40(1):121-38. [PubMed: 20630992]

8. Willett WC, et al. Weight, weight change, and coronary heart disease in women. Risk within the 'normal' weight range. Jama. 1995; 273(6):461-5. [PubMed: 7654270]

9. Ekblom-Bak E, et al. Independent associations of physical activity and cardiovascular fitness with cardiovascular risk in adults. Eur J Cardiovasc Prev Rehabil. 17(2):175-80.

10. Hamer M, et al. Physical activity and cardiovascular mortality risk: possible protective mechanisms? Med Sci Sports Exerc. 2012; 44(1):84-8. [PubMed: 21659902] 
11. Li J, Siegrist J. Physical activity and risk of cardiovascular disease--a meta-analysis of prospective cohort studies. Int J Environ Res Public Health. 2012; 9(2):391-407. [PubMed: 22470299]

12. Oguma Y, Shinoda-Tagawa T. Physical activity decreases cardiovascular disease risk in women: review and meta-analysis. Am J Prev Med. 2004; 26(5):407-18. [PubMed: 15165657]

13. Helmrich SP, et al. Physical activity and reduced occurrence of non-insulin-dependent diabetes mellitus. N Engl J Med. 1991; 325(3):147-52. [PubMed: 2052059]

14. Legrand FD, Thatcher J. Acute mood responses to a 15-minute long walking session at selfselected intensity: effects of an experimentally-induced telic or paratelic state. Emotion. 2011; 11(5):1040-5. [PubMed: 21517170]

15. Fretts AM, et al. Modest levels of physical activity are associated with a lower incidence of diabetes in a population with a high rate of obesity: the strong heart family study. Diabetes Care. 35(8):1743-5.

16. Jefferis BJ, et al. Longitudinal associations between changes in physical activity and onset of type 2 diabetes in older British men: the influence of adiposity. Diabetes Care. 35(9):1876-83.

17. McTiernan A, et al. Recreational physical activity and the risk of breast cancer in postmenopausal women: The Women's Health Initiative Cohort Study. Journal of the American Medical Association. 2003; 290(10):1331-6. [PubMed: 12966124]

18. Eliassen AH, et al. Physical activity and risk of breast cancer among postmenopausal women. Arch Intern Med. 2010; 170(19):1758-64. [PubMed: 20975025]

19. Monninkhof EM, et al. Physical activity and breast cancer: a systematic review. Epidemiology. 2007; 18(1):137-57. [PubMed: 17130685]

20. Slattery ML. Physical activity and colorectal cancer. Sports Med. 2004; 34(4):239-52. [PubMed: 15049716]

21. Boyle T, et al. Physical activity and risks of proximal and distal colon cancers: a systematic review and meta-analysis. J Natl Cancer Inst. 2012; 104(20):1548-61. [PubMed: 22914790]

22. Howard RA, et al. Physical activity, sedentary behavior, and the risk of colon and rectal cancer in the NIH-AARP Diet and Health Study. Cancer Causes Control. 2008; 19(9):939-53. [PubMed: 18437512]

23. Wolin KY, et al. Physical activity and colon cancer prevention: a meta-analysis. Br J Cancer. 2009; 100(4):611-6. [PubMed: 19209175]

24. Harris CD, et al. Adult participation in aerobic and muscle-strengthening physical activities-United States, 2011. Morbidity and Mortality Weekly Report. 2013; 62(17):326-30. [PubMed: 23636025]

25. Tucker JM, Welk GJ, Beyler NK. Physical activity in U.S.: adults compliance with the Physical Activity Guidelines for Americans. Am J Prev Med. 2011; 40(4):454-61. [PubMed: 21406280]

26. Skinner, BF. Science and Human Behavior. Cambridge, MA: B.F. Skinner Foundation; 1953.

27. Higgins, ST., Silverman, K., Heil, SH. Contingency management in substance abuse treatment. New York: Guilford; 2008.

28. King D, et al. Approaches based on behavioral economics could help nudge patients and providers toward lower health spending growth. Health Aff (Millwood). 2013; 32(4):661-8. [PubMed: 23569045]

29. Thaler, RH., Sunstein, CR. Nudge: Improving decisions about health, wealth, and happiness. Revised and expanded edition. New York: Penguin Books; 2009.

30. Ikeda S, Kang MI, Ohtake F. Hyperbolic discounting, the sign effect, and the body mass index. J Health Econ. 2010; 29(2):268-84. [PubMed: 20167384]

31. Ainslie, G. Breakdown of will. New York: Cambridge; 2001.

32. Gilbert DT, Wilson TD. Prospection: Experiencing the future. Science. 2007; 317(5843):1351-4. [PubMed: 17823345]

33. Kahneman, D., Snell, J. Predicting utility. In: Hogarth, R., editor. Insights in decision making. University of Chicago; Chicago: 1990.

34. Strohacker K, Galárraga O, Williams DM. The impact of incentives on exercise behavior: A systematic review of randomized controlled trials. Annals of Behavioral Medicine. 2014; 48:9299. [PubMed: 24307474] 
35. Strohacker K, et al. Impact of Small Monetary Incentives on Exercise in University Students. American journal of health behavior. 2015; 39(6):779-786. [PubMed: 26450545]

36. American College of Sports Medicine. ACSM's guidelines for exercise testing and prescription. 8. Philadelphia, PA: Lippincott, Williams, \& Wilkins; 2010.

37. YMCA. Available from: http://www.ymcagreaterprovidence.org/Membership/FinancialAid/ tabid/299/Default.aspx

38. Jones LW, et al. Effects of an oncologist's recommendation to exercise on self-reported exercise behavior in newly diagnosed breast cancer survivors: a single-blind, randomized controlled trial. Ann Behav Med. 2004; 28(2):105-13. [PubMed: 15454357]

39. Godin G, Shephard RJ. Godin Leisure-Time Exercise Questionnaire. Medicine and Science in Sports and Exercise. 1997; 29(June Supplement):S36-S38.

40. Rushton JP, Chrisjohn RD, Fekken GC. The altruistic personality and the self-report altruism scale. Personality and individual differences. 1981; 2(4):293-302.

41. Little, RJ., Rubin, DB. Statistical analyses with missing data. 2. Hoboken, NJ: John Wiley and Sons; 2002.

42. Cohen J. A power primer. Psychological Bulletin. 1992; 112(1):155-9. [PubMed: 19565683]

43. Warburton DE, Bredin SS. Reflections on physical activity and health: what should we recommend? Canadian Journal of Cardiology. 2016; 32(4):495-504. [PubMed: 26995692]

44. Dulin PL, Hill RD. Relationships between altruistic activity and positive and negative affect among low-income older adult service providers. Aging Ment Health. 2003; 7(4):294-9. [PubMed: 12888441]

45. Williams DM. Exercise, affect, and adherence: An integrated model and a case for self-paced exercise. Journal of Sport and Exercise Psychology. 2008; 30(5):471-96. [PubMed: 18971508]

46. Williams DM, et al. Acute affective response to a moderate-intensity exercise stimulus predicts physical activity participation 6 and 12 months later. Psychology of Sport and Exercise. 2008; 9(3):231-245. [PubMed: 18496608]

47. Williams DM, et al. Does affective valence during and immediately following a 10-min walk predict concurrent and future physical activity? Annals of Behavioral Medicine. 2012; 44(1):4351. [PubMed: 22532005]

48. NIHCA. National Independent Health Club Association. Economic incentives information. Available from: http://www.nihca.org/wp-content/uploads/2010/02/Program-Partners1.pdf

49. Robison JI, et al. Effects of a 6-month incentive-based exercise program on adherence and work capacity. Med Sci Sports Exerc. 1992; 24(1):85-93. [PubMed: 1549001]

50. Epstein LH, et al. Attendence and fitness in aerobics exercise: The effects of contracts and lottery procedures. Behavior Modification. 1980; 4:465-479.

51. Volpp KG, et al. Redesigning employee health incentives--lessons from behavioral economics. N Engl J Med. 2011; 365(5):388-90. [PubMed: 21812669] 


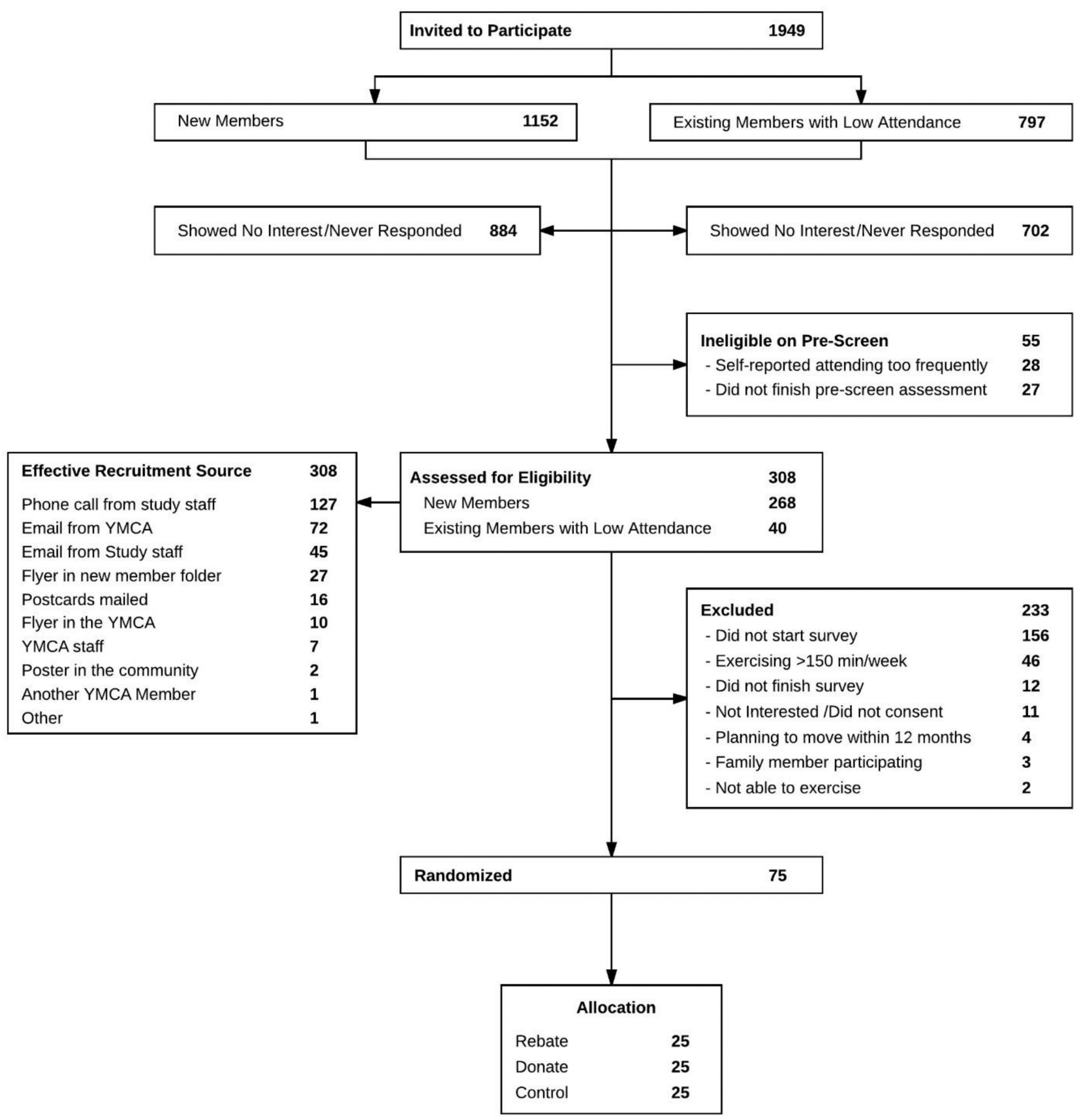

Figure 1.

Flow of participants from initial contact to randomization 
Table 1

Participant Characteristics - Categorical Variables

\begin{tabular}{|c|c|c|c|}
\hline & $\begin{array}{l}\text { Rebate } \\
\text { N }(\%)\end{array}$ & $\begin{array}{l}\text { Donate } \\
\mathbf{N}(\%)\end{array}$ & $\begin{array}{c}\text { Control } \\
\mathbf{N}(\%)\end{array}$ \\
\hline \multicolumn{4}{|l|}{ Gender } \\
\hline Male & $3(12)$ & $7(29.2)$ & $2(8)$ \\
\hline Female & $21(84)$ & $17(70.83)$ & $23(92)$ \\
\hline \multicolumn{4}{|l|}{ Highest Grade Completed } \\
\hline High School Graduate & $1(4)$ & $0(0)$ & $1(4)$ \\
\hline Some College & $9(36)$ & $6(25)$ & $5(20)$ \\
\hline College Graduate & $8(32)$ & $11(45.8)$ & $10(40)$ \\
\hline Post-graduate work & $6(24)$ & $7(29.2)$ & $8(32)$ \\
\hline \multicolumn{4}{|l|}{ Ethnicity } \\
\hline Asian & 0 & 0 & $1(4)$ \\
\hline Native Hawaiian /Other Pacific Islander & 0 & 0 & 0 \\
\hline Blank or African American & 0 & $1(4)$ & 0 \\
\hline White & $24(96)$ & $24(96)$ & $24(96)$ \\
\hline Other & $1(4)$ & 0 & 0 \\
\hline Hispanic or Latino & $1(4)$ & 0 & 0 \\
\hline \multicolumn{4}{|l|}{ Total Household Income } \\
\hline Less than $\$ 30,000$ & $5(20)$ & $6(24)$ & $3(12)$ \\
\hline Between $\$ 30-50,000$ & $8(32)$ & $7(28)$ & $7(28)$ \\
\hline Over $\$ 50,000$ & $11(44)$ & $11(44)$ & $12(48)$ \\
\hline Refused & $1(4)$ & $1(4)$ & $3(12)$ \\
\hline Employed & $11(44)^{*}$ & $18(72)^{*}$ & $18(72)^{*}$ \\
\hline \multicolumn{4}{|l|}{ Marital Status } \\
\hline Single & $3(12)$ & $9(36)$ & $6(24)$ \\
\hline Married/Partnered & $18(72)$ & $13(52)$ & $15(60)$ \\
\hline Widowed & $1(4)$ & 0 & $2(8)$ \\
\hline Separated/Divorced & $2(8)$ & $3(12)$ & $2(8)$ \\
\hline \multicolumn{4}{|l|}{ Number of Children under 18} \\
\hline None & $6(24)$ & $8(32)$ & $8(32)$ \\
\hline $1-3$ & $18(72)$ & $16(64)$ & $14(56)$ \\
\hline Four or more & 0 & 0 & $3(12)$ \\
\hline \multicolumn{4}{|l|}{ Number of Children under 5} \\
\hline None & $12(48)$ & $11(45.8)$ & $16(64)$ \\
\hline One or more & $12(48)$ & $13(52)$ & $8(32)$ \\
\hline
\end{tabular}


Table 2

Participant Characteristics - Continuous Variables

\begin{tabular}{lcccc}
\hline & $\begin{array}{c}\text { Total } \\
\text { Mean (SD) }\end{array}$ & $\begin{array}{c}\text { Rebate } \\
\text { Mean (SD) }\end{array}$ & $\begin{array}{c}\text { Donate } \\
\text { Mean (SD) }\end{array}$ & $\begin{array}{c}\text { Control } \\
\text { Mean (SD) }\end{array}$ \\
\hline Age (years) & $39.7(12.3)$ & $43.7(12.4)^{*}$ & $34.8(11.3)^{*}$ & $40.4(11.9)$ \\
Body Mass Index $\left(\mathrm{kg} / \mathrm{m}^{2}\right)$ & $30.6(7.8)$ & $31.4(9.7)$ & $29.9(6.6)$ & $30.4(6.9)$ \\
Godin Leisure Time Physical Activity (mins/week) & $38.5(42.4)$ & $38.2(38.6)$ & $34(41.5)$ & $43.2(47.9)$ \\
Altruism & $56.25 .2(10.5)$ & $56.0(11.2)$ & $55.6(9.2 .0)$ & $57.1 .1(11.2)$ \\
Hedonic Well-being & $4.4(0.7)$ & $4.5(0.75)$ & $4.3(0.76)$ & $4.36(0.68)$ \\
Eudaimonic Well-being & $24.0(3.8)$ & $24.5(3.7)$ & $23.1(3.9)$ & $24.3(3.9)$ \\
\hline
\end{tabular}

Note.

Indicates significant between-group differences. 